\title{
Fatigue in patients with low grade glioma: systematic evaluation of assessment and prevalence
}

\author{
Ellen M. P. van Coevorden-van Loon ${ }^{1,2}$ - Marijke B. Coomans ${ }^{2}$ • \\ Majanka H. Heijenbrok-Kal ${ }^{1,2} \cdot$ Gerard M. Ribbers $^{1,2} \cdot$ Martin J. van den Bent $^{3}$
}

Received: 25 January 2017 / Accepted: 27 April 2017 / Published online: 24 May 2017

(c) The Author(s) 2017. This article is an open access publication

\begin{abstract}
Fatigue is the most prevalent and disabling symptom in cancer patients. Yet, scientific literature on this topic is scarce and reports disparate results. This study systematically reviews how fatigue is assessed in patients with low-grade glioma and evaluates its prevalence in LGG patients. A systematic literature search was performed in PubMed, Embase and PsychINFO for articles reporting on fatigue in patients with LGG. Two reviewers independently extracted data from selected articles. Inclusion criteria were: (1) patients with suspected or confirmed LGG; (2) fatigue was assessed as primary or secondary outcome measure; (3) age $\geq 18$ years; (4) full-length article written in English or Dutch. In total, 19 articles were selected, including 971 patients. Seven self-assessment instruments were identified. Prevalence rates ranged from 39 to $77 \%$. Fatigue was found to be a common side effect of treatment. The prevalence rates ranged from 20 to $76 \%$ when fatigue was reported as a mild or moderate side effect and fatigue was prevalent in $4 \%$ when reported as a severe side effect. Fatigue is a common problem in LGG patients that warrants more therapeutic and scientific attention. Gaining
\end{abstract}

Ellen M. P. van Coevorden-van Loon and Marijke B. Coomans are the co first-authors.

Ellen M. P. van Coevorden-van Loon

EvCoevorden@rijndam.nl

1 Rotterdam Neurorehabilitation Research (RoNeRes), Rijndam Rehabilitation Center, PO Box 23181, 3001 KD Rotterdam, The Netherlands

2 Department of Rehabilitation Medicine, Erasmus MC, Rotterdam, The Netherlands

3 Department of Neurology/Neuro-oncology, Erasmus MC Cancer Institute, Rotterdam, The Netherlands deeper insight in the underlying mechanisms of fatigue is essential in targeting therapy to individual patients.

Keywords Fatigue $\cdot$ Low-grade glioma $\cdot$ Assesssment . Prevalence

\section{Introduction}

Fatigue, characterized by feelings of tiredness, weakness and lack of energy, is the most frequently reported symptom of cancer. In all different types of cancer fatigue is common, up to $99 \%$ of the patients experience fatigue during the treatment and follow up [1-3]. Fatigue is the most important cause of loss of quality of life both for the patient and the care giver $[4,5]$. Cancer-related fatigue is defined as a "persistent, subjective sense of tiredness related to cancer and cancer treatment that interferes with usual functioning" [6]. Despite its impact, fatigue in patients with cancer is underreported, underdiagnosed and undertreated [6]. Fatigue is a multidimensional concept. The National Comprehension Cancer Network (NCCN) has made an overview of coherent factors of the multidimensional concept of cancer-related fatigue, including: tumor-related factors and complications, comorbid conditions, psychological symptoms associated with the underlying tumor treatment, side effects of other medication, iatrogenic factors and psychological/behavioural factors [5].

This study focuses at patients with low grade glioma (LGG), defined as a grade I/II primary brain tumor arising from glial cells of the central nervous system including astrocytoma, oligodendroglioma, ependymoma or mixed glioma (oligoastrocytoma) according to the World Health Organization (WHO) [7]. Patients suffering from LGG have a median life expectancy of 5-15 years thanks 
to surgery, radiation and chemotherapy [2, 8-10]. There are few studies on the prevalence of fatigue in LGG patients. Proportions of fatigued in glioma patients vary from 39 to $77 \%[4,11]$ which may be explained by differences between assessment methods, patient populations, and definitions of fatigue.

With the increasing survival time there is a growing need for development and improvement of treatment programs for fatigue in LGG patients which should be based on the currently available evidence $[12,13]$. Therefore, the current systematic review was set up (1) to evaluate how fatigue is assessed in LGG patients, (2) to assess the prevalence of fatigue.

\section{Methods}

A systematic search was performed in PubMed, Embase and PsychInfo in March 2016 using the search strategy presented in Table 1. After study selection, reference lists of all selected studies were examined.

\section{Study selection}

All titles and abstracts were screened independently by two investigators using the following criteria: (1) the study population included patients with suspected or confirmed LGG, (2) fatigue was reported as an outcome measure, (3) patients were $\geq 18$ years of age at the time of diagnosis and (4) the publication was an original full-length manuscript in a peer-reviewed journal, written in English or Dutch. Studies including less than five patients and studies reporting duplicate data of previous studies were excluded. After a first selection of articles based on title/abstract, the full text manuscripts were retrieved and carefully assessed and evaluated according to the in- and exclusion criteria (Fig. 1). In case the authors disagreed, a third reviewer was consulted.

\section{Data extraction}

After the final selection, two authors independently extracted data from the selected articles using a standard data extraction form. In case of disagreement, a third reviewer was consulted. Studies were differentiated in studies with fatigue as primary or secondary outcome (group 1) and studies in which fatigue was only reported as a side effect of a (new) treatment therapy (group 2). In cases of missing data the corresponding authors were contacted by email [14-23]. The results of responding authors were included $[14,15,21]$.

\section{Data synthesis}

The focus of this systematic review was to study instruments used for the assessment of fatigue of patients with LGG in a qualitative way and to gain to more insight in the prevalence of fatigue. Therefore, the results of this review are presented in tables using descriptive statistics.

\section{Results}

The initial search identified 286 articles. After removal of duplicates in the three databases, the titles/abstracts of 215 studies were evaluated according to the inclusion criteria. A large number of articles $(n=107)$ were excluded because no LGG patients were included. Also, a relatively large number of articles were found to be abstracts of (oral) conference meetings $(n=24)$. Ultimately, 29 articles were screened in full text. The final dataset consisted of 19 articles that met all criteria. The characteristics of these studies are outlined in Table 2. A flowchart of the study selection is shown in Fig. 1.

\section{Study population}

Nineteen studies encompassed a total number of 917 LGG patients. Differentiation in type of glioma was reported for 886 patients (97\%). The most common diagnosis was

Table 1 Search strategy

\begin{tabular}{lc}
\hline Data source & Search terms \\
\hline Pubmed & $($ Glioma[mh] OR glioma*[tiab] OR astrocytoma*[tiab] OR ependymoma*[tiab] OR \\
& oligodendroma*[tiab]) AND (low grade*[tiab] OR grade I*[tiab] OR grade II*[tiab] OR grade \\
& $1 *[$ tiab] OR grade $2 *[$ tiab] OR grade1*[tiab] OR grade2*[tiab])) AND $(($ fatigue*[tiab])) \\
Embase & 'glioma'/exp OR glioma OR 'astrocytoma'/exp OR astrocytoma OR glioma**ab,ti OR \\
& astrocytoma*:ab,ti OR ependymoma*:ab,ti OR oligodendroma*:ab,ti AND ('low grade':ab,ti \\
& OR 'grade i':ab,ti OR 'grade ii':ab,ti OR 'grade 1':ab,ti OR 'grade 2':ab,ti OR 'grade1':ab,ti \\
& OR 'grade2':ab,ti) AND fatigue*:ab,ti \\
PsychINFO & (OR) glioma* astrocytoma* ependymoma* oligodendroma* (AND) (low grade) (AND) fatigue*
\end{tabular}


Fig. 1 Flowchart of study selection

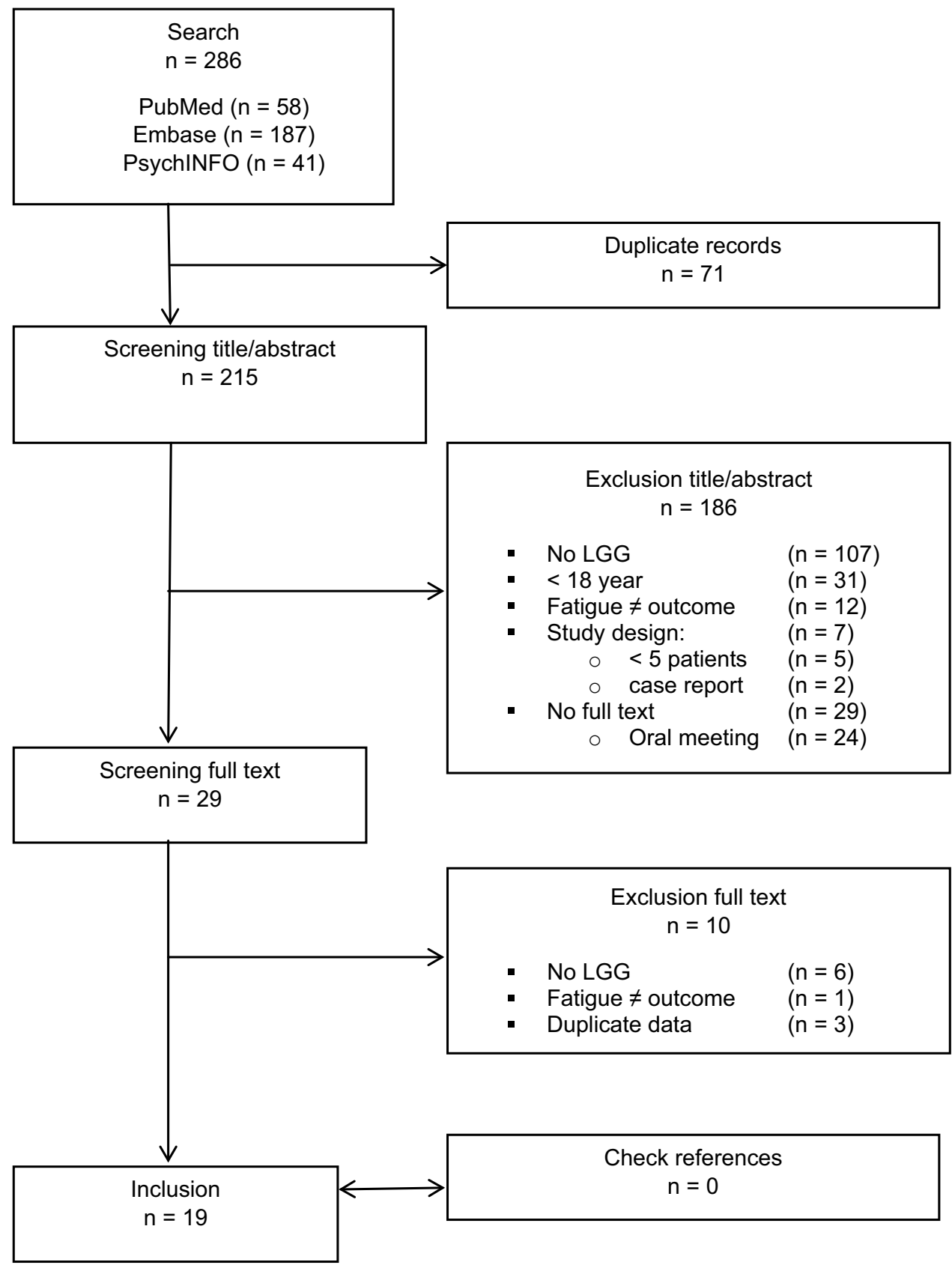

astrocytoma (55\%), followed by oligodendroglioma (22\%), oligoastrocytoma (12\%), ependymoma (9\%) and other/ unknown type of LGG (2\%). The mean age of the total population was 41.9 years. A description of the reported time post-diagnosis was available in $36 \%$ of the patients and ranged from 3.5 to 15 years. In $90 \%$ of the patients a complete description of treatment was provided. One study reported results prior to treatment [16]. In all other included studies, patients underwent some type of treatment. Most of the patients underwent partial or complete surgery $(80 \%)$, followed by radiotherapy $(68 \%)$, chemotherapy $(11 \%)$ or a combination. An overview of the study population characteristics reported in the included article is shown in Table 2.

\section{Results}

In 12 out of 19 studies fatigue was a primary or secondary outcome measure, defined as 'Group 1', representing $85 \%(n=753)$ of all patients. In eight studies fatigue was reported in the outcome category measure of adverse events. In that category, it was reported as a side effect of a treatment under study. These studies are defined as 'Group 2 ', representing $15 \%(n=134)$ of all patients. One study 


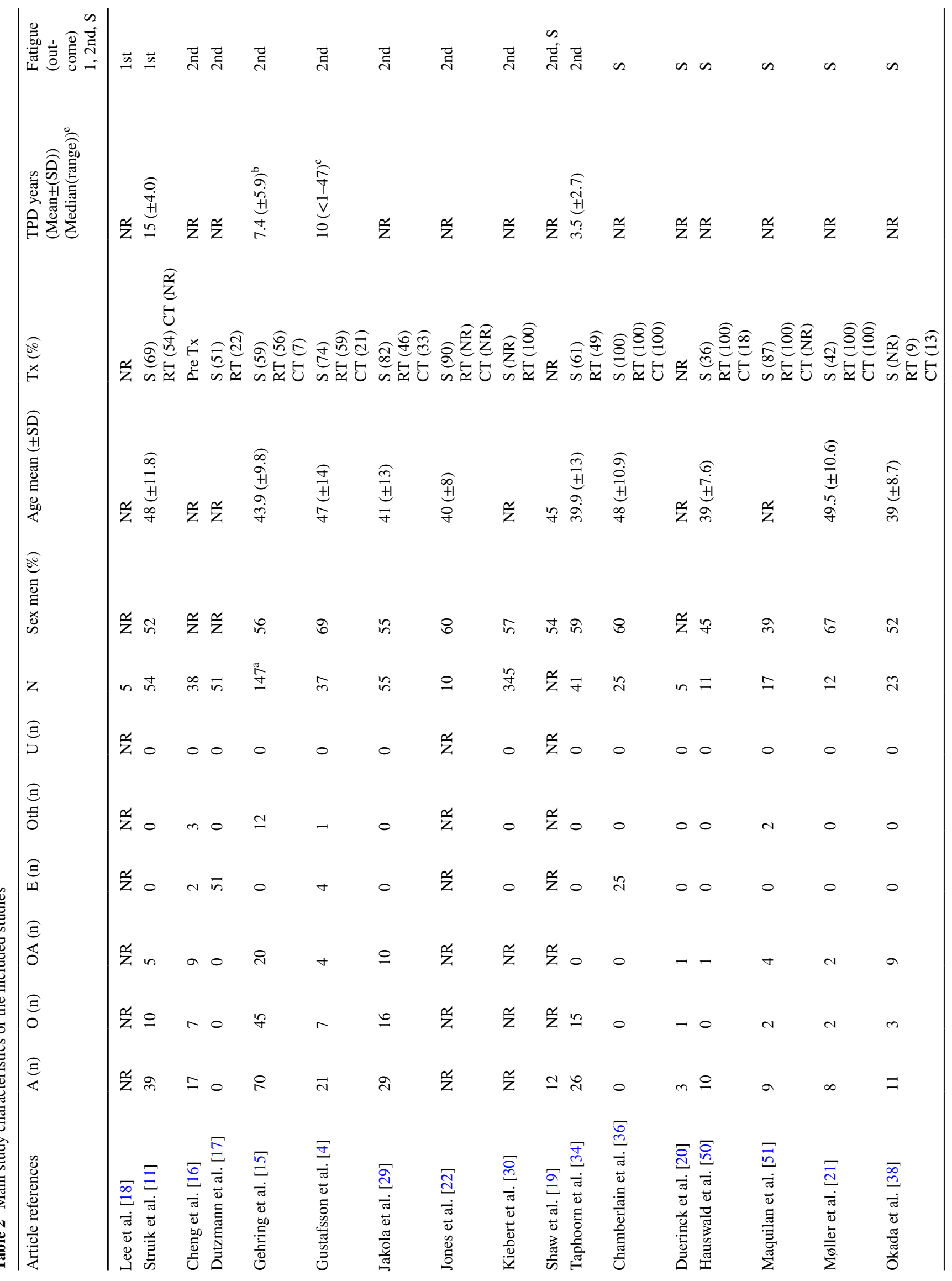




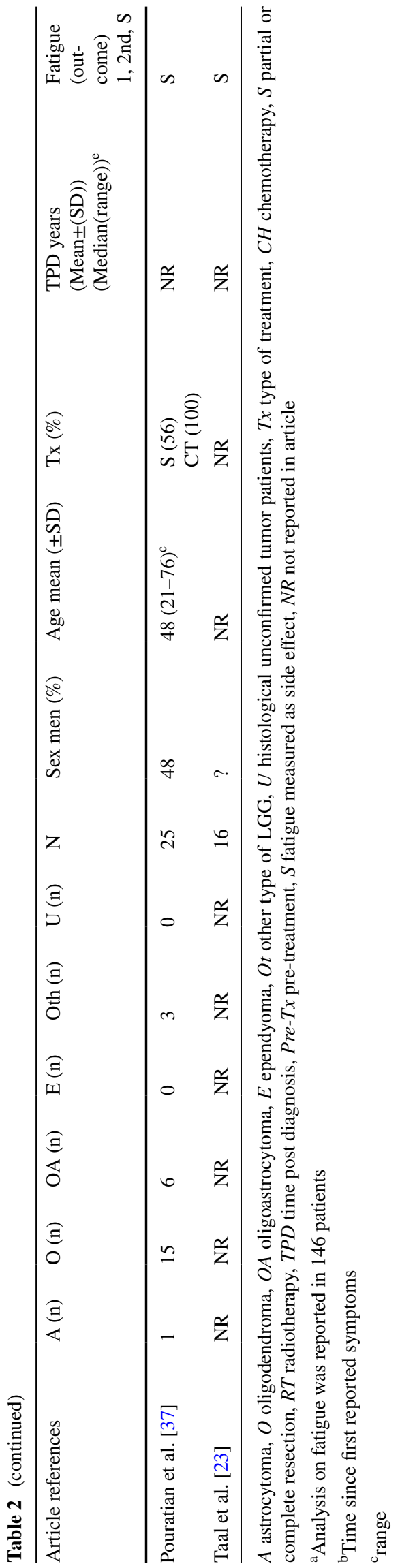

measured fatigue both as a primary outcome and as a side effect of treatment [19].

\section{Measurements}

In group 1 seven self-assessment instruments could be identified. Two studies used two or more instruments [18, 19]. Table 3 shows a short description and the internal consistency of the measurement instruments.

Three multidimensional fatigue scales were used in the articles: (1) the Cancer Fatigue Scale (CFS), (2) the checklist individual strength (CIS), and (3) the multidimensional fatigue inventory (MFI-20). The CFS consists of 15 items measuring physical, cognitive and activity-related fatigue [24]. One included study used the CFS [18]. The CIS consists of 20 items covering fatigue, fatigue severity ( 8 items), concentration problems (13 items), reduced motivation (4 items), and reduced activity (3 items) [25]. The CIS was used in one study [11]. The MFI-20 is a 20 -item scale designed to evaluate five dimensions of fatigue: general fatigue, physical fatigue, reduced motivation, reduced activity, and mental fatigue [26]. The MFI was used in one included study [14]. The CFS, CIS and MFI-20 are used across different patient populations, including cancer patients $[1,24,26]$. One unidimensional fatigue scale was used in the included articles: the brief fatigue inventory (BFI). The BFI is a nine-item instrument to assess fatigue on a rating scale. The BFI was developed for the rapid assessment of fatigue severity in cancer patients [27]. The scale was used in one article [18].

In three multidimensional instruments, fatigue was measured as a subdomain of health-related quality of life or mood: (1) The European Organization for Research and Treatment of Cancer Quality of Life Questionnaire (EORTC QLQ-C30), (2) The Functional Assessment of Cancer Therapy-Fatigue Scale (FACT-F) and (3) The Profile of Mood States (POMS). The European Organization for Research and Treatment of Cancer Quality of Life Questionnaire (EORTC QLQ-C30) is a quality-of-life scale that includes a three-item fatigue subscale which has been widely used as an independently validated fatigue measure across different oncological populations. It was specifically designed for use in oncology [28]. Five included studies used the EORT QLQ C30 [4, 16, 17, 29, 30]. The Functional Assessment of Cancer Therapy-Fatigue (FACT-F) subscale is part of a collection of quality of life questionnaires targeting the management of chronic illness. It consists of 13 items and is frequently used in cancer populations $[31,32]$. The FACT-F was assessed in two included studies $[18,22]$. The Profile of Mood States (POMS) contains several scales including a fatigue subscale of seven items which have been used both in cancer and non-cancer 


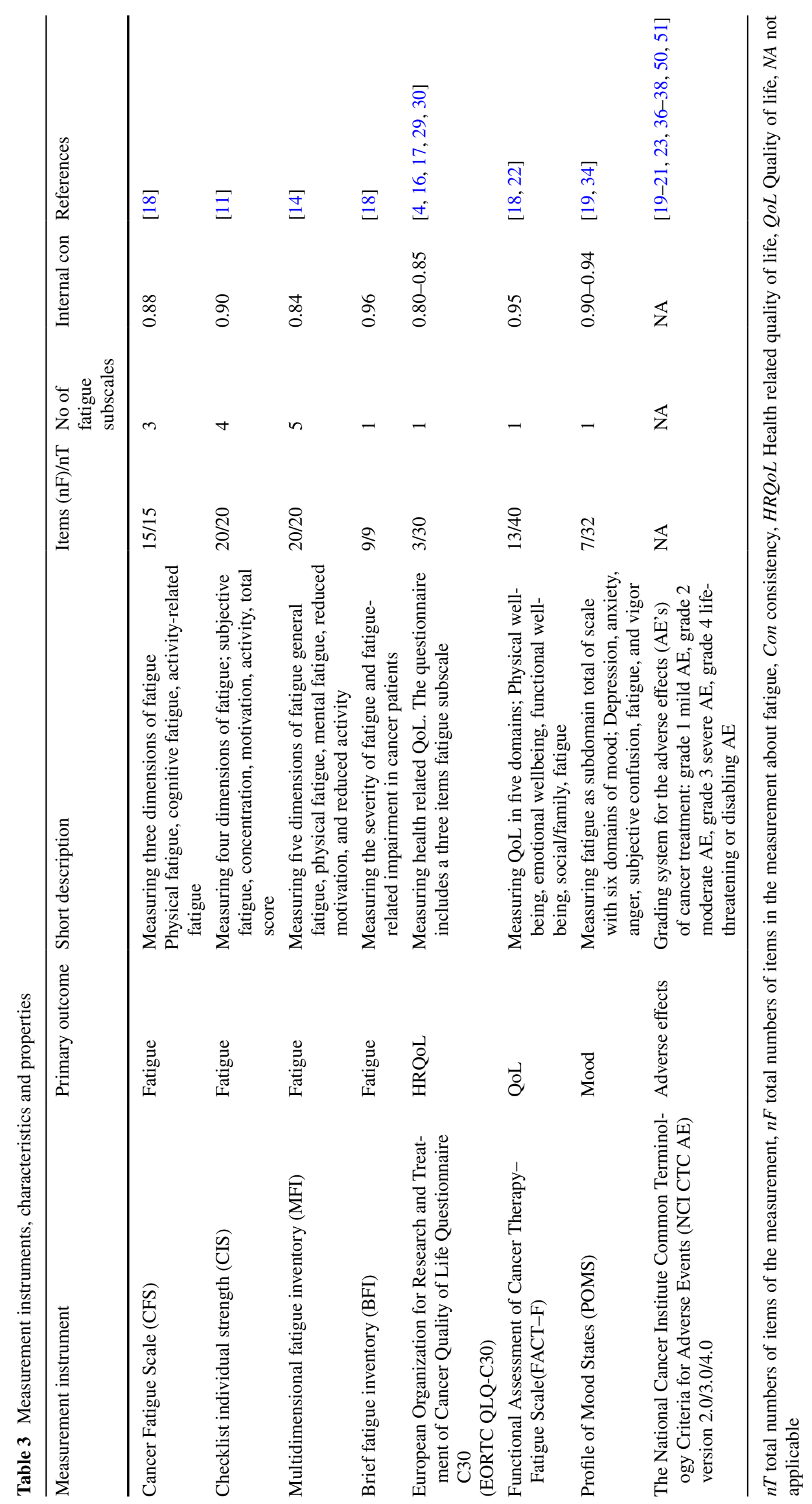


populations [33]. Two included studies used the POMS $[19,34]$.

In all studies reporting fatigue as side effect of treatment, the National Cancer Institute Common Terminology Criteria for Adverse Events (NCI CTCAE) was used. The NCI CTCAE is a set of standardised definitions for adverse events and describes the severity of organ toxicity for patients receiving cancer therapy [35]. The NCI CTCAE describes fatigue as a disorder characterized by a state of generalized weakness with a pronounced inability to summon sufficient energy to accomplish daily activities. In this review, the identified articles used version $2.0,3.0$ or 4.0. The adverse events (AE's) are defined based on grades one (mild), two (moderate), three (severe), four (life-threatening) and five (death related to $\mathrm{AE}$ ).

\section{Prevalence}

In group 1, the prevalence of fatigue was provided in three studies representing $19 \%$ of the total of included patients $(146 / 783)[4,11,29]$. The reported prevalence of fatigue ranged from $39 \%$ (long term surviving LGG patients experiencing severe fatigue) to $77 \%$ (feeling tired during the last week from "a little" to "very much"). Other results related to fatigue as an outcome measure were reported in $87 \%$ of the included patients (679/783). These results are shown in Table 4.

In group 2, a detailed description of fatigue as a side effect of treatment was provided in three studies, representing 54\% (73/134) of the patients [36-38]. The reported prevalence as a side effect of treatment ranged from 20 to $76 \%$ when fatigue was reported as a mild (grade 1) or moderate (grade 2), side effect. When reported as a severe (grade 3) side effect, fatigue was prevalent in $4 \%$ of the patients.

\section{Discussion}

This systematic review shows a variety of instruments that are used to measure fatigue in LGG patients. We identified seven self-assessment instruments (CFS, CIS, MFI, BFI, EORTC QOL-C30, FACT, POMS). All scales were used in a number of different cancer populations and have a good internal validity. Fatigue was the primary outcome only in two studies. In all other studies fatigue was a secondary outcome. When fatigue was reported as a side effect of treatment, the National Cancer Institute Common Terminology Criteria for Adverse Events is uniformly used. This is in agreement with the recommendation of the National Cancer Institute [35].

Table 4 Prevalence and severity of fatigue

\begin{tabular}{|c|c|c|}
\hline Article & Primary outcome study & Reported results on fatigue LGG \\
\hline Lee et al. [18] & Fatigue & NR \\
\hline Struik et al. [11] & Fatigue & $39 \%$ severe fatigue ${ }^{a}$ \\
\hline Cheng et al. [16] & HRQoL & NR \\
\hline Dutzmann et al. [17] & HRQoL & NR \\
\hline Gehring et al. [14] & Cognitive functioning & Above average score on scale "mental fatigue" \\
\hline Gustafsson et al. [4] & Function, HRQoL, coping & $77 \%$ feeling tired during the last week from a little to "very much"a \\
\hline Jakola et al. [29] & Overall survival, HRQoL & $\begin{array}{l}44 \% \text { experienced symptoms in at least one of the fatigue related } \\
\text { questions }^{\mathrm{a}}\end{array}$ \\
\hline Jones et al. [22] & Functional performance measures post-surgery & NR \\
\hline Kiebert et al. [30] & HRQoL & Low median scores were found for fatigue \\
\hline Shaw et al. [19] & Cognitive functioning, mood, and QoL & NR \\
\hline Taphoorn et al. [34] & QoL and cognitive functioning & $\begin{array}{l}\text { LGG patients scored higher on the subscales fatigue than did control } \\
\text { subjects }\end{array}$ \\
\hline Chamberlain et al. [36] & Side effect of CT & FG 1/2:20\% \\
\hline Duerinck et al. [20] & Side effect of CT & NR \\
\hline Møller et al. [21] & Side effect of CT & NR \\
\hline Pouratian et al. [37] & Side effect of CT & FG $1 / 2: 76 \%$ \\
\hline Taal et al. [23] & Side effect of CT & NR \\
\hline Okada et al. [38] & Side effect of IT & FG $1: 35 \%$, FG $2: 52 \%$, FG $3: 4 \%$ \\
\hline Hauswald et al. [50] & Side effect of RT & NR \\
\hline Maquilan et al. [51] & Side effect of RT & NR \\
\hline
\end{tabular}

$N R$ not reported, $F G$ fatigue grade of toxicity, $C T$ chemotherapy, $I T$ immunotherapy, $R T$ radiotherapy

${ }^{\mathrm{a}}$ Reported prevalence on fatigue 
The EORTC QOL-C30 is the most frequently used instrument included in this review. Unidimensional instruments or subscales measure the severity of perceived fatigue and tend to be short and easy-to-use. Also, they have the most robust psychometric data to support their use since they are widely used: the FACT and the EORTC QLQ-C30 have been used in over 10.000 patients [39, 40]. However, fatigue is a multidimensional concept involving mood disorders, anxiety, cognitive disorders and physical distress [5]. When the goal is to gain insight in fatigue, rather than only assess the level of perceived fatigue, a multidimensional fatigue instrument provides a more comprehensive view [3]. This is line with the Dutch oncology guidelines, that recommend to use the multidimensional fatigue instrument (MFI) for measuring cancer-related fatigue [41]. The MFI is considered to be the most frequently used multidimensional fatigue instrument in clinical care in the Netherlands and was found to be reliable, valid, easy to handle and responsive [26, 39, 41, 42]. Additionally, it must be taken into account that even multidimensional fatigue instruments will only gain insight in the subjective experience of fatigue since fatigue is self-reported. The patient's representations of their physical and cognitive functioning might not always correspond with objective measurement of physical activity, performance and cognitive functioning [43].

Fatigue is not only the most common symptom in cancer patients, but also a typical disabling symptom in neurological disorders such as stroke [44]. One theory of fatigue in patients with traumatic brain injury and stroke patients is the 'cognitive coping hypothesis'. This hypothesis states that patients with brain injury have to put in more effort to accomplish tasks, compared to non-injured individuals [45, 46]. For patients, this means that they tire more easily and they need longer to recuperate from fatigue then before the injury [45]. We think this theory can be one of the explanations for fatigue in LGG patients. Gehring et al. [15] found result that lower ratings of cognitive function in LGG patients were associated with self-reported mental fatigue, measured with the MFI. Research to analyse the factors of fatigue in low grade patients with subjective and objective measurement outcomes will be useful in developing individualized rehabilitation treatment programs in LGG patients with fatigue.

Because fatigue was a primary outcome in only two studies, we found limited information on prevalence rates. However, the included studies do show that fatigue seems to be a frequent problem prior to treatment [16], during radio- and chemotherapy $[17,30]$ and in the long term after treatment [11]. This is in line with patients with brain tumours of different origins than LGG $[1,47]$. Unfortunately, this review was not able to distinguish the different contributions in terms of fatigue from different treatment modalities. It can be stated that fatigue is a common side effect of these treatments, as is known from the literature [48]. Fatigue is both a frequent symptom of LGG as a side effects of its treatment and the relative effects of the disease versus treatment are difficult to distinguish. This is a major challenge in clinical decision making, weighing the benefits against the adverse effects of treatment. In newly diagnosed LGG patients the risks and benefits of treatment strategies including resection, radiation, chemotherapy or "watchful waiting" are recommended to be individually weighed [41, 49].

\section{Conclusion}

Despite the growing awareness of cancer-related fatigue, there is still a lack of knowledge of the exact pathophysiology of fatigue and the underlying mechanisms of fatigue in LGG patients. This review shows that fatigue is a common problem in LGG patients, both as a disease symptom and as a side effect of treatment. Measurement of fatigue is complex and multiple instruments need to be used for proper assessment. Incorporation of the patients' perspective (patient reported outcome) with a multidimensional fatigue instrument is in line with the current guidelines. Additionally, it must be taken into account that even multidimensional fatigue instruments not yield sufficient insight in potential causes or consequences of fatigue, like a decrease in physical and cognitive performance. We suggest research to analyse the factors of fatigue in low grade patients with subjective and objective measurement outcomes to developing individualized rehabilitation treatment programs in LGG patients.

Open Access This article is distributed under the terms of the Creative Commons Attribution 4.0 International License (http:// creativecommons.org/licenses/by/4.0/), which permits unrestricted use, distribution, and reproduction in any medium, provided you give appropriate credit to the original author(s) and the source, provide a link to the Creative Commons license, and indicate if changes were made.

\section{References}

1. Servaes P, Verhagen C, Bleijenberg G (2002) Fatigue in cancer patients during and after treatment: prevalence, correlates and interventions. Eur J cancer 38:27-43. doi:10.1016/ S0959-8049(01)00332-X

2. Wang XS, Zhao S, Fisch MJ, O'Mara AM, Cella D, Mendoza TR, Cleeland CS (2014) Prevalence and characteristics of moderate-to-severe fatigue: a multicenter study in cancer patients and survivors. Cancer 120:425-432. doi:10.1002/cncr.28434

3. Ahlberg K, Ekman T, Gaston-Johansson F, Mock V (2003) Assessment and management of cancer-related fatigue in adults. Lancet 362:640-650. doi:10.1016/S0140-6736(03)14186-4

4. Gustafsson M, Edvardsson T, Ahlström G (2006) The relationship between function, quality of life and coping in patients 
with low-grade gliomas. Support Care Cancer 14:1205-1212. doi:10.1007/s00520-006-0080-3

5. Mock V, Atkinson A, Barsevick A, Cella D, Cimprich B, Cleeland C, Donnelly J, Eisenberger M, Escalante C, Hinds P (2000) NCCN practice guidelines for cancer-related fatigue. Oncology 14:151-161

6. Mock V, Abernethy AP, Atkinson A, Barsevick AM, Berger AM, Cella D, Cimprich B, Cleeland C, Eisenberger MA, Escalante CP (2007) Cancer-related fatigue clinical practice guidelines in oncology. J Natl Compr Cancer Netw 5:1054-1078

7. Grier JT, Batchelor T (2006) Low-grade gliomas in adults. Oncologist 11:681-693. doi:10.1634/theoncologist.11-6-681

8. Shields LB, Choucair AK (2014) Management of low-grade gliomas: a review of patient-perceived quality of life and neurocognitive outcome. World Neurosurg 82:e299-e309. doi:10.1016/j. wneu.2014.02.033

9. van den Bent MJ (2014) Practice changing mature results of RTOG study 9802: another positive PCV trial makes adjuvant chemotherapy part of standard of care in low-grade glioma. Neuro-oncol 16:1570-1574. doi:10.1093/neuonc/nou297

10. Soffietti R, Baumert B, Bello L, Von Deimling A, Duffau H, Frénay M, Grisold W, Grant R, Graus F, Hoang-Xuan K (2010) Guidelines on management of low-grade gliomas: report of an EFNS-EANO* Task Force. Eur J Neurol 17:1124-1133

11. Struik K, Klein M, Heimans JJ, Gielissen MF, Bleijenberg G, Taphoorn MJ, Reijneveld JC, Postma TJ (2009) Fatigue in low-grade glioma. J Neuro-oncol 92:73-78. doi:10.1007/ s11060-008-9738-7

12. Buckner JC, Shaw EG, Pugh SL, Chakravarti A, Gilbert MR, Barger GR, Coons S, Ricci P, Bullard D, Brown PD (2016) Radiation plus procarbazine, CCNU, and vincristine in low-grade glioma. N Engl J Med 374:1344-1355

13. Smith JS, Chang EF, Lamborn KR, Chang SM, Prados MD, Cha S, Tihan T, VandenBerg S, McDermott MW, Berger MS (2008) Role of extent of resection in the long-term outcome of lowgrade hemispheric gliomas. J Clin Oncol 26:1338-1345

14. Gehring K, Sitskoorn MM, Gundy CM, Sikkes SAM, Klein M, Postma TJ, van den Bent MJ, Beute GN, Enting RH, Kappelle AC, Boogerd W, Veninga T, Twijnstra A, Boerman DH, Taphoorn MJB, Aaronson NK (2009) Cognitive rehabilitation in patients with gliomas: a randomized, controlled trial. J Clin Oncol 27:3712-3722. doi:10.1200/JCO.2008.20.5765

15. Gehring K, Taphoorn MJB, Sitskoorn MM, Aaronson NK (2015) Predictors of subjective versus objective cognitive functioning in patients with stable grades II and III glioma. Neuro-Oncol Pract 2:20-31. doi:10.1093/nop/npu035

16. Cheng JX, Liu BL, Zhang X, Lin W, Zhang YQ, Liu WP, Zhang JN, Lin H, Wang R, Yin H (2010) Health-related quality of life in glioma patients in China. BMC Cancer 10:305. doi:10.1186/1471-2407-10-305

17. Dutzmann S, Schatlo B, Lobrinus A, Murek M, Wostrack M, Weiss C, Schaller K, Raabe A, Meyer B, Goldbrunner R, Franz K, Seifert V, Senft C (2013) A multi-center retrospective analysis of treatment effects and quality of life in adult patients with cranial ependymomas. J Neurooncol 114:319-327. doi:10.1007/ s11060-013-1187-2

18. Lee EQ, Muzikansky A, Drappatz J, Kesari S, Wong ET, Fadul CE, Reardon DA, Norden AD, Nayak L, Rinne ML (2016) A randomized, placebo-controlled pilot trial of armodafinil for fatigue in patients with gliomas undergoing radiotherapy. NeuroOncology. doi:10.1093/neuonc/now007

19. Shaw EG, Rosdhai R, D'Agostino Jr RB, Lovato J, Naughton MJ, Robbins ME, Rapp SR (2006) Phase II study of donepezil in irradiated brain tumor patients: effect on cognitive function, mood, and quality of life. J Clin Oncol Off J Am Soc Clin Oncol 24:1415-1420. doi:10.1200/JCO.2005.03.3001
20. Duerinck JDF S, Sander W, Van Binst AM, Everaert H, Michotte A, Hau P, Neyns B (2015) Sunitinib malate plus lomustine for patients with temozolomide-refractory recurrent anaplastic or low-grade glioma. Anticancer Res 35:5551-5558

21. Møller S, Grunnet K, Hansen S, Schultz H, Holmberg M, Sørensen MM, Poulsen HS, Lassen U (2012) A phase II trial with bevacizumab and irinotecan for patients with primary brain tumors and progression after standard therapy. NeuroOncology 12:iv73. doi:10.3109/0284186X.2012.681063

22. Jones LW Mourtzakis M, Peters KB, Friedman AH, West MJ, Mabe SK, Kraus WE, Friedman HS, Reardon DA (2010) Changes in functional performance measures in adults undergoing chemoradiation for primary malignant glioma: a feasibility study. Oncologist 15:636-647. doi:10.1634/ theoncologist.2009-0265

23. Taal W, Segers-van Rijn JM, Kros JM, van Heuvel I, van der Rijt CC, Bromberg JE, Smitt PAS, van den Bent MJ (2012) Dose dense 1 week on/1 week off temozolomide in recurrent glioma: a retrospective study. J Neuro-Oncol 108:195-200. doi:10.1007/s11060-012-0832-5

24. Okuyama T, Akechi T, Kugaya A, Okamura H, Shima Y, Maruguchi M, Hosaka T, Uchitomi Y (2000) Development and validation of the cancer fatigue scale: a brief, three-dimensional, self-rating scale for assessment of fatigue in cancer patients. J Pain Symptom Manag 19:5-14

25. Vercoulen JH, Swanink CM, Fennis JF, Galama JM, van der Meer JW, Bleijenberg G (1994) Dimensional assessment of chronic fatigue syndrome. J Psychosom Res 38:383-392

26. Smets E, Garssen B, Bonke Bd, De Haes J (1995) The multidimensional fatigue inventory (MFI) psychometric qualities of an instrument to assess fatigue. J Psychosom Res 39:315-325. doi:10.1016/0022-3999(94)00125-O

27. Mendoza TR, Wang XS, Cleeland CS, Morrissey M, Johnson BA, Wendt JK, Huber SL (1999) The rapid assessment of fatigue severity in cancer patients. Cancer 85:1186-1196. doi:10.1002/(SICI)1097-0142(19990301)85:5<1186::AIDCNCR24>3.0.CO;2-N

28. Aaronson NK, Ahmedzai S, Bergman B, Bullinger M, Cull A, Duez NJ, Filiberti A, Flechtner H, Fleishman SB, de Haes JC (1993) The European Organization for Research and Treatment of Cancer QLQ-C30: a quality-of-life instrument for use in international clinical trials in oncology. J Natl Cancer Inst 85:365-376. doi:10.1093/jnci/85.5.365

29. Jakola AS, Unsgard G, Myrmel KS, Kloster R, Torp SH, Lindal S, Solheim O (2012) Low grade gliomas in eloquent locations-implications for surgical strategy, survival and long term quality of life. PLoS ONE 7(12):e51450. doi:10.1371/ journal.pone. 0051450

30. Kiebert GM Curran D, Aaronson NK, Bolla M, Menten J, Rutten EH, Nordman E, Silvestre ME, Pierart M, Karim AB (1998) Quality of life after radiation therapy of cerebral lowgrade gliomas of the adult: results of a randomised phase III trial on dose response (EORTC trial 22844). EORTC Radiotherapy Co-operative Group. Eur J Cancer 34:1902-1909. doi:10.1016/S0959-8049(98)00268-6

31. Yellen SB, Cella DF, Webster K, Blendowski C, Kaplan E (1997) Measuring fatigue and other anemia-related symptoms with the functional assessment of cancer therapy (FACT) measurement system. J Pain Symptom Manag 13:63-74. doi:10.1016/S0885-3924(96)00274-6

32. Weitzner MA, Meyers CA, Gelke CK, Byrne K, Cella D, Levin V (1995) The functional assessment of cancer therapy (FACT) scale. Cancer 75:1151-1161. doi:10.1002/1097-0142(19950301)75:5<1151::AIDCNCR2820750515>3.0.CO;2-Q 
33. Terry PC, Lane AM, Fogarty GJ (2003) Construct validity of the profile of mood states - adolescents for use with adults. Psychol Sport Exercise 4:125-139. doi:10.1016/S1469-0292(01)00035-8

34. Taphoorn MJ, Schiphorst AK, Snoek FJ, Lindeboom J, Wolbers JG, Karim AB, Huijgens PC, Heimans JJ (1994) Cognitive functions and quality of life in patients with low-grade gliomas: the impact of radiotherapy. Ann Neurol 36:48-54. doi:10.1002/ ana.410360111

35. Trotti A, Colevas AD, Setser A, Rusch V, Jaques D, Budach V, Langer C, Murphy B, Cumberlin R, Coleman CN (2003) CTCAE v3. 0: development of a comprehensive grading system for the adverse effects of cancer treatment. Semin Radiat Oncol 13(3):176-181. doi:10.1016/S1053-4296(03)00031-6

36. Chamberlain MC, Johnston SK (2009) Temozolomide for recurrent intracranial supratentorial platinum-refractory ependymoma. Cancer 115:4775-4782. doi:10.1002/cnvr.245324

37. Pouratian N, Gasco J, Sherman JH, Shaffrey ME, Schiff D (2006) Toxicity and efficacy of protracted low dose temozolomide for the treatment of low grade gliomas. J Neurooncol 82:281-288. doi:10.1007/s11060-006-9280-4

38. Okada H, Butterfield LH, Hamilton RL, Hoji A, Sakaki M, Ahn BJ, Kohanbash G, Drappatz J, Engh J, Amankulor N, Lively MO, Chan MD, Salazar AM, Shaw EG, Potter DM, Lieberman FS (2015) Induction of robust type-I CD8 + T-cell responses in WHO grade 2 low-grade glioma patients receiving peptidebased vaccines in combination with poly-ICLC. Clin Cancer Res 21:286-294. doi:10.1158/1078-0432.CCR-14-1790

39. Minton O, Stone P (2008) A systematic review of the scales used for the measurement of cancer-related fatigue (CRF). Annals Oncol. doi:10.1093/annonc/mdn537

40. Zikos E, Coens C, Quinten C, Ediebah DE, Martinelli F, Ghislain I, King MT, Gotay C, Ringash J, Velikova G (2016) The added value of analyzing pooled health-related quality of life data: a review of the EORTC PROBE initiative. J Natl Cancer Inst. doi:10.1093/jnci/djv391
41. Oncoline (2011) Richtlijnen Oncologisch Zorg. Integraal Kankercentrum Nederland. http://www.oncoline.nl/index.php?pagina $=/$ richtlijn/item/pagina.php\&id=32533\&richtlijn_id=765

42. Agasi-Idenburg C, Velthuis M, Wittink H (2010) Quality criteria and user-friendliness in self-reported questionnaires on cancer-related fatigue: a review. J Clin Epidemiol 63:705-711. doi:10.1016/j.jclinepi.2009.08.027

43. Leavitt VM, DeLuca J (2010) Central fatigue: issues related to cognition, mood and behavior, and psychiatric diagnoses. PM\&R 2:332-337

44. Chaudhuri A, Behan PO (2004) Fatigue in neurological disorders. The lancet 363:978-988. doi:10.1016/ S0140-6736(04)15794-2

45. Zedlitz A, Fasotti L, Geurts A (2011) Post-stroke fatigue: a treatment protocol that is being evaluated. Clin Rehabil 25:487-500

46. Zedlitz AM, Rietveld TC, Geurts AC, Fasotti L (2012) Cognitive and graded activity training can alleviate persistent fatigue after stroke a randomized, controlled trial. Stroke 43:1046-1051

47. Asher A, Fu JB, Bailey C, Hughes JK (2016) Fatigue among patients with brain tumors. CNS Oncol 5:91-100. doi:10.2217/ cns-2015-0008

48. Hofman M, Ryan JL, Figueroa-Moseley CD, Jean-Pierre P, Morrow GR (2007) Cancer-related fatigue: the scale of the problem. Oncologist 12:4-10. doi:10.1634/theoncologist.12-S1-4

49. Berger MS, Weller M (2016) Gliomas. Academic Press, Amsterdam

50. Hauswald H, Rieken S, Ecker S, Kessel KA, Herfarth K, Debus J, Combs SE (2012) First experiences in treatment of low-grade glioma grade I and II with proton therapy. Radiat Oncol 7(1):189

51. Maquilan G, Grover S, Alonso-Basata M, Lustig RA (2014) Acute toxicity profile of patients with low-grade gliomas and meningiomas receiving proton therapy. Am J Clin Oncol 37(5):438-443. doi:10.1097/COC.0b013e31827de86b 